Category: Original article

\title{
Postoperative Complications Do Not Impact on Recurrence and Survival after Curative Resection of Gastric Cancer
}

Short title: Impact of Postoperative Events

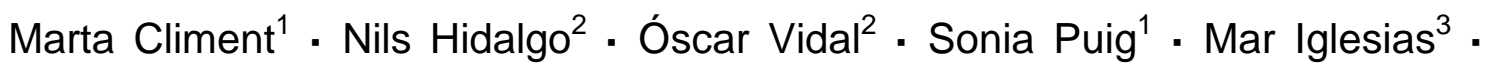
Miriam Cuatrecasas ${ }^{4}$ - José M Ramón ${ }^{1} \cdot$ Xabier García-Albéniz $^{5}$ - Luís Grande ${ }^{1}$ - Manuel Pera ${ }^{1}$

${ }^{1}$ Section of Gastrointestinal Surgery, Hospital Universitario del Mar, IMIM (Institut Hospital del Mar d’Investigacions Mèdiques), Universitat Autónoma de Barcelona, Barcelona, Spain; '2Department of General and Digestive Surgery, Hospital Clínic, Universitat de Barcelona, Barcelona, Spain; ${ }^{3}$ Service of Pathology, Hospital Universitario del Mar, Barcelona, Spain; ${ }^{4}$ Service of Pathology, Hospital Clínic, Barcelona, Spain; and ${ }^{5}$ Department of Epidemiology. Harvard T.H. Chan School of Public Health, Boston, USA.

Corresponding author: Manuel Pera, MD, PhD, Section of Gastrointestinal Surgery, Hospital Universitario del Mar, Passeig Marítim 25-29, E-08003 Barcelona, Spain. Phone: +34 93 2483207, fax: +34 932483433, e-mail: pera@parcdesalutmar.cat

Grant support: None.

Presented at the International Surgical Congress of the Association of Surgeons of Great Britain and Ireland (ASGBI), Harrogate, UK, April 2014. 


\section{Abstract (word count 241)}

Background: The influence of major postoperative complications on the oncological outcome in patients with upper gastrointestinal (Gl) cancer remains controversial. We assessed the impact of complications on recurrence and survival after curative gastric cancer resection.

Methods: A retrospective review of a prospectively maintained database was undertaken to identify patients undergoing R0 resections between 1990 and 2009. Patients were categorized by presence of any complication ClavienDindo $(C D) \geq I l$, sepsis or intra-abdominal sepsis. Cox regression analyses to relate complications and clinico-pathological variables to time to recurrence (TTR) and overall survival (OS) were performed.

Results: A total of 271 patients were included with a median follow-up of 149.9 months (range 140.1-159.9). Complications CD $\geq 1$ occurred in 162 (59.8\%) patients, sepsis in 66 (22.5\%), and intraabdominal sepsis in 37 (13.6\%). Tumor recurrence developed in 88 (32.4\%) patients. At multivariate analysis, independent predictors of short TTR were PTNM stage (IIIB-IIIC vs. IA-IIA) (hazard ratio $[\mathrm{HR}]=37.55,95 \%$ confidence interval $[\mathrm{Cl}] 17.57-80.24 ; \mathrm{p}<0.001$ ), D1 lymphadenectomy (HR=3.14, 95\% $\mathrm{Cl} 1.94-5.07 ; p<0.001)$, and male gender $(\mathrm{HR}=1.65,95 \% \mathrm{Cl} 1.06-2.57 ; \mathrm{p}=0.026)$. In relation to $\mathrm{OS}$, multivariate analysis identified pTNM stage (IIIB-IIIC versus IA-IIA, HR= 10.28, 95\% Cl 6.51-16.23; $p<0.001)$, male gender $(H R=1.64,95 \% \mathrm{Cl} 1.17-2.31 ; p=0.005)$, age $(H R=1.03$, $95 \% \mathrm{Cl} 1.02-1.05 ; \mathrm{p}<0.001)$, and adjuvant therapy $(\mathrm{HR}=0.55,95 \% \mathrm{Cl} 0.37-$ $0.83 ; p=0.004)$ as independent predictors. 
Conclusions: Evidence provided by this study does not support a negative impact of postoperative complications $\mathrm{CD}>\mathrm{II}$, sepsis, and intraabdominal sepsis on the oncologic outcome after curative gastric cancer resection.

Key words: gastric cancer; postoperative complications; recurrence; survival 


\section{Introduction}

Gastrointestinal cancer surgery is associated with high rates of postoperative complications. It has been suggested that these complications may promote tumor recurrence and decrease long-term survival, particularly in colorectal cancer surgery [1-3]. This relationship appears to be stronger for infectious complications [4]. Conflicting results have been reported regarding the association between postoperative complications and poor survival after resection of oesophageal cancer [5-7]. A more consistent relationship, however, has recently been described for gastric cancer resection, mainly in series from Eastern Asia, although differences in classifying or grading complications make these results still unclear [8-12]. It appears plausible that these results can be extrapolated to Western series where the incidence of overall and infectious postoperative complications, as well as the percentage of cases with advanced stages (II-III) are higher as compared with Eastern Asia series [13].

Clinical and experimental data suggest that persistent systemic inflammatory response by infectious complications may promote tumor recurrence and progression after cancer surgery $[14,15]$. It is worthwhile to assess the impact of septic events (sepsis and intraabdominal sepsis) uniformly classified on the oncologic outcome of patients undergoing curative gastric cancer resection.

The purpose of the present study was to examine the effects of postoperative complications especially those associated with a systemic inflammatory response, on recurrence and long-term survival after curative surgery for gastric cancer. 


\section{Methods}

\section{Study population}

Between January 1990 and December 2009, 315 consecutive patients with gastric adenocarcinoma underwent $\mathrm{R} 0$ resection at the Gastrointestinal Surgical Units of Hospital Universitario del Mar and Hospital Clínic, in Barcelona, Spain. A specialized team following similar perioperative protocols over the time frame of the study performed gastric resection with associated lymphadenectomy. Given the time span of patients included in the study, the extent of lymphadenectomy varied but D2 dissection without splenectomy was commonly performed. The Institutional Review and Boards of both participating hospitals approved data collection and analysis.

Clinicopathological data and follow-up status for all operated patients were collected from a prospectively maintained database, which was common to both institutions. Two experienced pathologists (M.I., M.C) re-reviewed all diffuse and mixed type adenocarcinomas to identify signet ring cell (SRC) types, defined according to World Health Organization criteria [16]. Tumors were reclassified according to the seventh UICC/TNM classification system [17].

In the context of clinical trials carried out during the study period $[18,19]$, patients with pathological stage (pStage) II/III disease were treated with adjuvant chemotherapy, which consisted of mitomycin C (MMC), $10-20 \mathrm{mg} / \mathrm{m}^{2}$ i.v. bolus 4 courses (period 1990-1994) or MMC plus Tegafur $500 \mathrm{mg} / \mathrm{m}^{2}$ p.o daily for 6 months (since 1995 to 2004). After 2004, adjuvant chemoradiation therapy was also indicated in patients with a high number of affected nodes.

\section{Definition of Postoperative Complications}


Complications were categorized into five grades according to the modified Clavien-Dindo (CD) classification [20]. If multiple complications occurred, the higher grade was used. For the purpose of this study, patients with $C D \geq I$ were considered as the "complication group". Additionally, the Comprehensive Complication Index $(\mathrm{CCl})$ was calculated as the sum of all complications that are weighted for their severity [21]. The final formula yields a continuous scale to rank the severity of any combination of complications from 0 to 100 in a single patient.

Perioperative blood transfusion (PBT) was defined as transfusion of allogenic red blood cells from 30 days before surgery until hospital discharge [22]. Indication of blood transfusion was left to the discretion of the treating physician. Sepsis was defined as an infection that had evoked a systemic inflammatory response syndrome (SIRS) [23]. Respiratory septic complications included pneumonia (defined as new or progressive infiltrate on chest X-ray, accompanied by fever/leukocytosis or leukopenia and purulent sputum, for which antibiotics treatment was started) and pleural empyema. Wound infection was defined as purulent drainage from the deep or superficial incision. Intraabdominal sepsis origins included anastomotic leakage (defined as full thickness gastrointestinal [GI] defect involving the anastomosis), duodenal stump fistula (bile or purulent drainage from a drain placed close to the duodenal stump), intraabdominal abscess (fluid collection diagnosed by ultrasound [US] or computed tomography [CT] with positive culture), pancreatic fistula (drain output with amylase content), and cholecystitis. Catheter-related bloodstream infection was defined as bacteraemia/fungemia in a patient with an intravascular catheter with at least one positive blood culture obtained from a 
peripheral vein and no other apparent source for the bloodstream infection except the catheter. Finally, catheter-related urinary tract infection (patient had an indwelling urinary catheter and positive urine culture) was also considered.

\section{Follow-up}

All patients were seen at the outpatient clinic by a medical oncologist and a surgeon at 3 months intervals during the first 2 years after operation, and every 6 months thereafter for 3 years. After 5 years, patients were followed every year. At follow-up patients underwent clinical examination, biochemistry with serum tumor markers (CEA and CA 19.9) and abdominal CT alternating with ultrasound examination every 6 months. More specific examinations (upper gastrointestinal endoscopy, laparoscopy, magnetic resonance imaging [MRI], or bone scintigraphy) were performed according to the patient's clinical condition. Histological confirmation of tumor recurrence was sought in all instances. Follow-up was extended to December 2012 ensuring a minimal potential followup of 36 months.

\section{Statistical Analysis}

Data are shown as frequencies and percentages for categorical variables or as median (interquartile range, percentile 25th-75th) for quantitative variables.

TTR was defined as the time from the date of surgery to the date of the first confirmed recurrence. OS was calculated from the date of surgery until death from any cause or the date of last follow-up in living patients. Median follow-up time was calculated using the reverse Kaplan-Meier method. Time to recurrence (TTR) and overall survival (OS) were the primary endpoints of the 
study. Kaplan-Meier curves were plotted and compared using log-rank statistics. A Cox proportional hazards regression model was used to assess the effects of covariates on TTR and OS for both bivariate and multivariate analyses. Variables achieving a probability value of less than 0.1 in the bivariate analysis or those considered clinically relevant were subsequently entered in the multivariate proportional Cox hazards regression analysis. Then, variables without significance in the model were removed manually one by one, attending a possible confounding factor, until obtaining a final predictor model. Results are expressed as hazard ratio $(\mathrm{HR})$ with $95 \%$ confidence interval $(95 \% \mathrm{Cl})$. Statistical significance was set at $P<0.05$ (two-sided). The SPSS software package (SPSS Inc, Chicago, IL, USA), version 18.0, was used to manage patient data and to perform statistical analyses. 


\section{Results}

Of the 315 eligible patients, $44(14 \%)$ patients were excluded from the analysis for the following reasons: 18 received neoadjuvant therapy, 11 underwent surgery for gastric stump carcinoma, 6 patients presented with a synchronous primary tumor at the time of diagnosis, and 9 patients died before postoperative day 60. The demographic details and clinicopathological characteristics of the 271 patients finally included in the study are shown in Table1.

\section{Complications}

One hundred sixty-two patients (59.8\%) developed complications CD $\geq$ II (II: 116 [42.8\%], IIla: 23 [8.5\%], IIIb: 13 [4.8\%], IVa: 6 [2.2\%], IVb: 4 [1.5\%]). A comparison of patient's characteristics between groups with and without complications is depicted in Table 1. Median CCI was 20.9 (0-30.8) points. The PBT rate in the series was 45\% (122 patients); only 7 patients received exclusively preoperative blood transfusion. In more than half of the patients with CD grade II (52\%), PBT was the sole complication.

Sixty-six out of 271 patients (22.5\%) developed 84 septic complications. Intra-abdominal sepsis was the most common event (37 patients; 13.6\%), followed by respiratory sepsis (19 patients; $7.0 \%$ ), catheter-related bloodstream infection (14 patients; 5.2\%), urinary tract infection (8 patients; $2.9 \%$ ), and wound infection (6 patients; 2.2\%). Eleven of these patients had two or more septic events. 


\section{Follow-up}

The median follow-up was 149.9 months (range 140.1-159.7). Nine patients (3.3\%) were lost to follow-up. We confirmed by reviewing data from the National Mortality Register that 7 of these 9 patients died with a median survival of 157 months after surgery. At the end of the study, 87 patients died from gastric cancer recurrence, 59 due to causes unrelated to gastric cancer, 7 from unknown causes, and 2 (one with confirmed recurrence) were lost to follow-up. A total of 116 remained alive.

\section{Recurrence and Risk Factors Related to the Time to Recurrence}

During the follow-up period, a total of $88(33.4 \%)$ recurrences occurred in 271 patients. Thirty-one patients developed recurrence within 12 months, 62 within 24 months, 73 within 36 months, 81 within 48 months, for a total of 85 at 5 years. Three patients developed late recurrences $(74,85$ and 117 months after surgery; liver metastasis, bone metastasis and gastric stump relapse, respectively). The median time to death after the diagnosis of recurrence was 4.2 (range 1.9-9.2) months.

In the bivariate analysis, weight loss $>10 \%$, tumor location other than in the antropyloric region, total gastrectomy, diffuse-type adenocarcinoma, lymphatic invasion, vascular invasion, perineural invasion, advanced pTstage, advanced pNstage and advanced PTNM stage were all factors negatively influencing recurrence (Table 2). However, postoperative complications CD grade $\geq$ II, sepsis, intra-abdominal sepsis and PBT were not associated with a lower probability of being free of recurrence (Figure 1). Time to recurrence 
curves stratified by pStage in patients with and without complications $(C D \geq I$, sepsis) did not show statistically differences (data not shown).

In the multivariate Cox regression analysis, male gender (HR 1.65, 95\% Cl 1.06-2.57; $p=0.026$ ), extent of lymphadenectomy D1 (HR 3.14, 95\% Cl 1.94-5.07; $p<0.001$ ), and advanced pTNM stage (IIB-IIIA versus IA-IIA HR 6.10, 95\% Cl 2.79-13.37; $p<0.001$, IIIB-IIIC versus IA-IIA HR $37.55,95 \% \mathrm{Cl}$ 17.57-80.24; $p<0.001$ ) remained as independent negative factors for the development of recurrence disease.

\section{Survival and Risk Factors Related to OS}

The cumulative $1,3,5$, and 10-year OS for the study cohort were $87.8 \%$, $66.3 \%, 55.8 \%$ and $48.1 \%$ from the date of surgery, respectively.

The bivariate analysis retained age, weight loss $>10 \%$, cardiac comorbidities, lymphatic invasion, perineural invasion, pT4 stage, pN stage, and advanced pTNM stage as factors negatively influencing overall survival (Table 3). OS was not significantly lower for patients who had complications $C D \geq I I$, postoperative sepsis and intraabdominal sepsis than for those without. Patients not receiving PBT showed significantly higher OS (Figure 1).

Multivariate analysis identified age (HR 1.03, 95\% Cl 1.02-1.05; $\mathrm{p}<$ 0.001), male gender ( $\mathrm{HR} 1.64,95 \% \mathrm{Cl} 1.17-2.31, \mathrm{p}=0.005)$, and advanced pTNM stage (IIB-IIIA versus IA-IIA, HR 2.40, 95\% Cl 1.50-3.84; $p<0.001$, IIIBIIIC versus IA-IIA, HR 10.28, 95\% Cl 6.51-16.23; $\mathrm{p}<0.001$ ) as independent negative factors affecting survival. On the other hand, adjuvant therapy showed an independent protective effect (HR 0.55, 95\% Cl 0.37-0.83; $\mathrm{p}=0.004)$. 
Influence of Complications Clavien-Dindo $\geq I I$, Sepsis, and Intraabdominal Sepsis on TTR and OS

Additional multivariate analyses adjusting each complication category (complications $C D \geq I$, sepsis, and intraabdominal sepsis) for patient, disease and treatment-related variables were performed using two models (Table 4). In both models, complications $C D \geq I$, sepsis, and intraabdominal sepsis were not associated with a significantly shorter time to recurrence or worse long-term OS. 


\section{Discussion}

This study in 271 patients undergoing curative resection for gastric cancer does not provide evidence supporting that either postoperative complication classified as Clavien-Dindo $\geq \|$ or sepsis or intraabdominal sepsis had a negative effect on tumor recurrence and OS. Advanced pathologic stage, however, remained as the most powerful predictor of recurrence and survival. Adjuvant therapy had a beneficial effect on OS.

The potential negative effect of postoperative complications and, in particular infectious complications, on long-term oncologic outcome after curative surgery for gastrointestinal cancer has been mainly examined in the setting of colorectal cancer [1-4]. A recent meta-analysis demonstrated that anastomotic leakage increases the risk of local tumor recurrence and reduces long-term cancer-specific survival after curative resection for rectal cancer [1]. Some groups have reported contradictory results especially when the impact of anastomotic leakage on tumor recurrence and survival was analyzed in patients after colonic anastomosis only.

Also, there is conflicting evidence regarding the effects of postoperative complications on long-term survival after resection for esophageal and gastric cancer. In esophageal cancer, four research groups have reported no effect of surgical complications on overall and disease-specific survival [5,24-26]. Four other studies $[6,7,27,28]$, however, have found a correlation between postoperative complications and decreased OS, shorter time interval until death due to cancer and early recurrence.

To date, only seven studies, six of them from Eastern Asia, have analyzed the influence of postoperative complications on the oncologic outcome 
in patients undergoing gastric cancer resection $[8-10,12,29,30]$. Their findings support a negative effect of anastomotic leakage $[9,29]$, postoperative infection [8,30], intraabdominal infection [10], or complications Clavien-Dindo $\geq$ II [12] on recurrence and survival after gastric cancer resection. The results of the present study, however, do not replicate these findings, even in a more adverse scenario with a higher rate of complications and more advanced tumor stages (stages II-III, 74.6\%). Postoperative complications occurred at a high rate of $61 \%$ in our study cohort, which is higher than what has been reported in series from Japan and Korea assessing the same question. It is of interest that PBT accounted for half of our reported Clavien-Dindo II complications (42.8\%). The present study, confirming the results of two recent large series, shows that PBT is not an independent prognostic factor for OS in patients having curative gastric cancer resection $[31,32]$.

As complications Clavien-Dindo $\geq \|$ include not only infectious complications, we specifically assessed the impact of sepsis after carefully having identified all infections that induced a systemic inflammatory response syndrome, but even in this setting no impact on recurrence and long-term OS was found.

The present findings should be interpreted taking into account the limitation of the retrospective design of the study covering a 20 -year period (1990-2009) and the relatively small series of patients. Although we are aware of the wide time span of the study and that this might include heterogeneity in the perioperative care of the patients, further adjustment per year of surgery in the multivariate models did not affect the results obtained (see models "2" in Table 4). It should be noted that patient data was collected prospectively by the 
same surgeon (M.P), surgery was performed by a reduced specialised team leaded by the same surgeon (M.P) in both institutions, and the follow-up assessment was achieved, in collaboration with the same oncologists, with a high degree of compliance during the whole study period. The potential impact of adjuvant therapy variability was limited as we mostly used the same protocol. Taking into account the sample size and the event rate in the group of patients without postoperative complications, our study had a $80 \%$ of power to detect a $13 \%$ increase in 5-year overall survival and a $15 \%$ increase in 5-year recurrence-free survival due to complications classified as Clavien-Dindo $\geq I I$. Thus, besides the lack of a true association, the absence of a statistically significant association could be due to (i) the presence of an association smaller than those depicted above or, (ii) a type II error (20\%). The apparent high mortality due to unrelated causes (59 patients) can be explained as the mean age of our patients was high at the time of surgery (almost 70 years) and the follow-up period was very long. In fact, the majority of patients died due to cardiovascular (47\%) or respiratory $(25 \%)$ causes. Despite the lack of an effect on recurrence and survival, a priority for improvement should be to reduce postoperative complications after curative gastric cancer surgery.

In conclusion, our results do not support the hypothesis that postoperative complications Clavien-Dindo $\geq \mathrm{II}$, sepsis, and intraabdominal sepsis have a negative impact on the oncologic outcome after curative gastric cancer surgery, which seems to depend mostly on the pathological stage of the disease. 


\section{Acknowledgments}

The authors wish to acknowledge Sergi Mojal, from the Statistics Unit, IMIM (Institut Hospital del Mar d'Investigacions Mèdiques) for expert help in the statistical analysis, Marta Pulido, MD, for editing the manuscript and editorial assistance, and Professor Jan van Lanschot (Department of Surgery, Erasmus Medical Centre, Rotterdam, The Netherlands) for helpful discussions.

Conflicts of interest: None to be disclosed by any of the authors. 


\section{References}

1. Mirnezami A, Mirnezami R, Chandrakumaran K, Sasapu K, Sagar P, Finan P. Increased local recurrence and reduced survival from colorectal cancer following anastomotic leak: systematic review and meta-analysis. Ann Surg $2011 ; 253: 890-899$.

2. Ptok H, Marusch F, Meyer F, Schubert D, Gastinger I, Lippert H. Impact of anastomotic leakage on oncological outcome after rectal cancer resection. Br J Surg 2007; 94:1548-1554.

3. Katoh H, Yamashita K, Wang G, Sato T, Nakamura T, Watanabe M. Anastomotic leakage contributes to the risk for systemic recurrence in stage II colorectal cancer. J Gastrointest Surg 2011; 15:120-129.

4. Artinyan A, Orcutt ST, Anaya DA, Richardson P, Chen GJ, Berger DH. Infectious postoperative complications decrease long-term survival in patients undergoing curative surgery for colorectal cancer: A study of 12,075 patients. Ann Surg 2015;261:497-505.

5. Ancona E, Cagol M, Epifani M, Cavallin F, Zaninotto G, Castoro C, Alfieri R, Ruol A. Surgical complications do not affect longterm survival after esophagectomy for carcinoma of the thoracic esophagus and cardia. J Am Coll Surg 2006; 203:661-669.

6. Lerut T, Moons J, Coosemans W, Van Raemdonck D, De Leyn P, Decaluwé H, Decker G, Nafteux P. Postoperative complications after transthoracic esophagectomy for cancer of the esophagus and gastroesophageal junction are correlated with early cancer recurrence: role of systematic grading of complications using the modified Clavien classification. Ann Surg 2009; 250:798-807. 
7. Lagarde SM, de Boer JD, ten Kate FJ, Busch OR, Obertop H, van Lanschot JJ. Postoperative complications after esophagectomy for adenocarcinoma of the esophagus are related to timing of death due to recurrence. Ann Surg $2008 ; 247: 71-76$.

8. Tsujimoto $H$, Ichikura $T$, Ono $S$, Sugasawa $H$, Hiraki $S$, Sakamoto $N$, Yaguchi Y, Yoshida K, Matsumoto Y, Hase K. Impact of postoperative infection on long-term survival after potentially curative resection for gastric cancer. Ann Surg Oncol 2009; 16:311-318.

9. Yoo HM, Lee HH, Shim JH, Jeon HM, Park CH, Song KY. Negative impact of leakage on survival of patients undergoing curative resection for advanced gastric cancer. J Surg Oncol 2011; 104:734-740.

10. Tokunaga M, Tanizawa Y, Bando E, Kawamura T, Terashima M. Poor survival rate in patients with postoperative intra-abdominal infectious complications following curative gastrectomy for gastric cancer. Ann Surg Oncol 2013; 20:1575-1583.

11. Li QG, Li P, Tang D, Chen J, Wang DR. Impact of postoperative complications on long-term survival after radical resection for gastric cancer. World J Gastroenterol 2013; 19:4060-4065.

12. Kubota T, Hiki N, Sano T, Nomura S, Nunobe S, Kumagai K, Aikou S, Watanabe $R$, Kosuga $T$, Yamaguchi $T$. Prognostic significance of complications after curative surgery for gastric cancer. Ann Surg Oncol 2014;21:891-898.

13. Bartlett EK, Roses RE, Kelz RR, Drebin JA, Fraker DL, Karakousis GC. Morbidity and mortality after total gastrectomy for gastric malignancy using the American College of Surgeons National Surgical Quality Improvement 
Program database. Surgery 2014;156:298-304.

14. Bohle B, Pera M, Pascual M, Alonso S, Mayol X, Salvado M, Schmidt J, Grande L. Postoperative intra-abdominal infection increases angiogenesis and tumor recurrence after surgical excision of colon cancer in mice. Surgery 2010; 147:120-126.

15. Salvans S, Mayol X, Alonso S, Messeguer R, Pascual M, Mojal S, Grande L, Pera M. Postoperative peritoneal infection enhances migration and invasion capacities of tumor cells in vitro: An insight into the association between anastomotic leak and recurrence after surgery for colorectal cancer. Ann Surg 2014; 260:939-943.

16. Watanabe H, Jass JR, Sobin LH. Histological typing of oesophageal and gastric tumors. WHO international histological classification of tumors. 2nd Ed ed. Berlin: Springer-Verlag; 1990.

17. Sobin LH, Gospodarowicz M, Wittekind C. TNM Classification of Malignant Tumors. 7th ed. New York: Wiley-Blackwell; 2009.

18. Grau JJ, Martin M, Fuster J, Pera M, Garcia-Valdecasas JC, Bombi JA, Bordas JM, Alcobendas F, Grande L, Estapé J. Impact of adjuvant chemotherapy in the long-term outcome of patients with resected gastric cancer. J Surg Oncol 2003; 82:234-240.

19. Grau JJ, Palmero R, Marmol M, Domingo-Domenech J, Monzo M, Fuster J, Vidal O, Fondevila C, Garcia-Valdecasas JC. Time-related improvement of survival in resectable gastric cancer: the role of Japanese-style gastrectomy with D2 lymphadenectomy and adjuvant chemotherapy. World J Surg Oncol 2006; 4:53. doi: 10.1186/1477-7819-4-53.

20. Clavien PA, Barkun J, de Oliveira ML, Vauthey JN, Dindo D, Schulick RD, 
de Santibañes E, Pekolj J, Slankamenac K, Bassi C, Graf R, Vonlanthen R, Padbury R, Cameron JL, Makuuchi M. The Clavien-Dindo classification of surgical complications: five-year experience. Ann Surg 2009; 250:187-196.

21. Slankamenac K, Graf R, Barkun J, Puhan MA, Clavien PA. The comprehensive complication index: a novel continuous scale to measure surgical morbidity. Ann Surg 2013; 258:1-7.

22. Mynster T, Christensen IJ, Moesgaard F, Nielsen HJ. Effects of the combination of blood transfusion and postoperative infectious complications on prognosis after surgery for colorectal cancer. Danish RANX05 Colorectal Cancer Study Group. Br J Surg 2000; 87:1553-1562.

23. Bone RC, Balk RA, Cerra FB, Dellinger RP, Fein AM, Knaus WA, Schein RM, Sibbald WJ. Definitions for sepsis and organ failure and guidelines for the use of innovative therapies in sepsis. The ACCP/SCCM Consensus Conference Committee. American College of Chest Physicians/Society of Critical Care Medicine. 1992. Chest 2009; 136 (5 Suppl):e28.

24. Junemann-Ramirez M, Awan MY, Khan ZM, Rahamim JS. Anastomotic leakage post-esophagogastrectomy for esophageal carcinoma: retrospective analysis of predictive factors, management and influence on longterm survival in a high volume centre. Eur J Cardiothoracic Surg 2005; 27:3-7.

25. Hii MW, Smithers BM, Gotley DC, Thomas JM, Thomson I, Martin I, Barbour AP. Impact of postoperative morbidity on long-term survival after oesophagectomy. Br J Surg 2013; 100:95-104.

26. Lindner K, Fritz M, Haane C, Senninger N, Palmes D, Hummel $R$. Postoperative complications do not affect long-term outcome in esophageal 
cancer patients. World J Surg 2015; 39:1322-1324.

27. Rutegard M, Lagergren $\mathrm{P}$, Rouvelas I, Mason R, Lagergren J. Surgical complications and long-term survival after esophagectomy for cancer in a nationwide Swedish cohort study. Eur J Surg Oncol 2012; 38:555-561.

28. Rizk NP, Bach PB, Schrag D, Bains MS, Turnbull AD, Karpeh M, Brennan MF, Rusch VW. The impact of complications on outcomes after resection for esophageal and gastroesophageal junction carcinoma. J Am Coll Surg 2004; 198:42-50.

29. Sierzega M, Kolodziejczyk P, Kulig J, Polish Gastric Cancer Study G. Impact of anastomotic leakage on long-term survival after total gastrectomy for carcinoma of the stomach. Br J Surg 2010; 97:1035-1042.

30. Hayashi T, Yoshikawa T, Aoyama T, Hasegawa S, Yamada T, Tsuchida K, Fujikawa H, Sato T, Ogata T, Cho H, Oshima T, Rino Y, Masuda M. Impact of infectious complications on gastric cancer recurrence. Gastric Cancer 2015;18:368-374.

31. Pacelli F, Rosa F, Marrelli D, Pedrazzani C, Bossola M, Zoccali M, Marchet A, Di Cosmo M, Roata C, Graziosi L, Cavazzoni E, Covino M, D'Ugo D, Roviello F, Nitti D, Doglietto GB. Do perioperative blood transfusions influence prognosis of gastric cancer patients? Analysis of 927 patients and interactions with splenectomy. Ann Surg Oncol 2011; 18:1615-1623.

32. Zhou HY, Yi W, Wang J, Zhang J, Wang WJ, Hu ZQ. Association of perioperative allogeneic blood transfusions and prognosis of patients with gastric cancer after curative gastrectomy. Am J Surg 2014; 208:80-87. 
Table 1. Clinicopathological characteristics of the study patients

\begin{tabular}{|c|c|c|c|c|}
\hline & $\begin{array}{l}\text { Entire group } \\
\quad(n=271)\end{array}$ & $\begin{array}{c}\text { Non-complication } \\
\text { group } \\
(\mathrm{n}=109)\end{array}$ & $\begin{array}{l}\text { Complication } \\
\text { group } \\
(n=162)\end{array}$ & $\boldsymbol{P}^{\star \star \star}$ \\
\hline Year surgery & & & & 0.750 \\
\hline 1990-1999 & $129(47.6)$ & $56(51.4)$ & $73(45.1)$ & \\
\hline 2000-2009 & $142(52.4)$ & $53(48.6)$ & $89(54.9$ & \\
\hline Gender & & & & 0.871 \\
\hline Male & $160(59)$ & 65 (59.6) & 95 (58.6) & \\
\hline Female & $111(41)$ & $44(40.4)$ & $67(41.4)$ & \\
\hline Age, mean (SD) & $69(7)$ & $65.5(13.6)$ & $71.9(10.5)$ & $<0.0001$ \\
\hline Comorbidities & & & & \\
\hline Diabetes & $51(18.8)$ & $18(16.5)$ & $33(20.4)$ & 0.426 \\
\hline$C O P D$ & $41(15.1)$ & $16(14.7)$ & $25(15.4)$ & 0.865 \\
\hline Weight loss & & & & \\
\hline$<10 \%$ & $241(88.9)$ & $97(89)$ & $144(88.9)$ & 0.979 \\
\hline$\geq 10 \%$ & $30(11.1)$ & $12(11)$ & $18(11.1)$ & \\
\hline Cirrhosis & $8(3)$ & $3(2.8)$ & $5(3.1)$ & 0.979 \\
\hline Cardiovascular & $121(44.6)$ & 38 (34.9) & $83(51.2)$ & 0.008 \\
\hline ASA score & & & & 0.016 \\
\hline I & $59(21.7)$ & 21(19.2) & $38(23.4)$ & \\
\hline II & 157 (57.9) & $74(67.8)$ & $83(51.6)$ & \\
\hline III & 51 (18.8) & 14 (13.3) & $37(23)$ & \\
\hline IV & $4(1.5)$ & $0(0)$ & $4(2.5)$ & \\
\hline Gastrectomy & & & & 0.868 \\
\hline Total & $150(55.4)$ & $61(56)$ & 89 (54.9) & \\
\hline Subtotal & $121(44.6)$ & $48(44)$ & $73(45.1)$ & \\
\hline Lymphadenectomy & & & & 0.712 \\
\hline D1 & $88(32.5)$ & 34 (31.2) & 54 (33.3) & \\
\hline$D 2$ & $183(67.5)$ & 75 (68.8) & $108(67.7)$ & \\
\hline Splenectomy & $57(21)$ & $23(21.1)$ & $34(21)$ & 0.982 \\
\hline Multivisceral resection & $54(19.9)$ & $23(21.1)$ & $31(19.1)$ & 0.691 \\
\hline Adjuvant therapy & $116(42.8)$ & 53 (48.6) & 63 (38.9) & 0.112 \\
\hline Tumor location & & & & 0.442 \\
\hline Antropyloric & $134(49.4)$ & $51(46.8)$ & $83(51.6)$ & \\
\hline Non-antropyloric & $137(50.5)$ & $58(53.2)$ & 79 (48.7) & \\
\hline Laurén classification ${ }^{a}$ & & & & 0.555 \\
\hline Intestinal & $154(56.8)$ & $62(57.4)$ & $92(59.3)$ & \\
\hline Diffuse & $100(36.9)$ & 44 (40.7) & $56(36.1)$ & \\
\hline Mixed & $9(3.3)$ & $2(1.9)$ & 7 (4.5) & \\
\hline Signet-ring cell ${ }^{a}$ * & $26(9.5)$ & $15(14.2)$ & $11(7)$ & 0.057 \\
\hline Grade differentiation & & & & 0.903 \\
\hline Good & $20(7.4)$ & $9(8.3)$ & $11(6.8)$ & \\
\hline Moderate & 108 (39.9) & $43(39.4)$ & $65(40.1)$ & \\
\hline Poor & $143(52.7)$ & 57 (52.3) & $86(53.1)$ & \\
\hline Lymphatic invasion & $78(28)$ & $26(23.9)$ & $50(31.6)$ & 0.165 \\
\hline Vascular invasion & $53(19.6)$ & $20(18.3)$ & $33(21)$ & 0.592 \\
\hline Perineural invasion & $61(22.5)$ & $18(16.5)$ & $43(27.4)$ & 0.038 \\
\hline pT category ${ }^{* *}$ & & & & 0.605 \\
\hline pT1a & $21(7.7)$ & $9(8.3)$ & $12(7.4)$ & \\
\hline pT1b & $36(13.3)$ & $18(16.1)$ & $18(11.1)$ & \\
\hline pT2 & $32(11.8)$ & $12(11)$ & 20 (12.3) & \\
\hline pT3 & 95 (35.5) & $39(35.8)$ & $56(34.6)$ & \\
\hline pT4a & $80(29.5)$ & $30(27.5)$ & $50(30.9)$ & \\
\hline pT4b & 7 (2.6) & $1(0.9)$ & $6(3.7)$ & \\
\hline
\end{tabular}


Table 1. Clinicopathological characteristics of the study patients (continued)

\begin{tabular}{|l|c|c|l|l|}
\hline pN category & & & & 0.979 \\
pNO & $123(45.3)$ & $50(45.9)$ & $73(45.1)$ & \\
pN1 & $48(17.7)$ & $19(17.4)$ & $29(17.9)$ & \\
pN2 & $40(14.8)$ & $17(15.6)$ & $23(14.2)$ & \\
pN3 & $60(22.1)$ & $23(21.1)$ & $37(22.8)$ & \\
pTNM stage & & & & 0.737 \\
la & $48(17.7)$ & $23(21.1)$ & $25(15.4)$ & \\
Ib & $22(8.1)$ & $10(9.2)$ & $12(7.4)$ & \\
Ila & $48(17.7)$ & $17(15.6)$ & $31(19.1)$ & \\
Ilb & $49(18.1)$ & $17(15.6)$ & $32(19.8)$ & \\
IIIa & $26(9.6)$ & $12(11)$ & $14(8.6)$ & \\
IIIb & $40(14.8)$ & $17(15.6)$ & $23(14.2)$ & \\
IIlc & $38(14)$ & $13(11.9)$ & $25(15.4)$ & \\
\hline
\end{tabular}

*According to World Health Organization (WHO) criteria [16]. ${ }^{* *}$ According to the 7 th edition of the International Union Against Cancer tumor node metastasis staging system [17]. COPD, chronic obstructive pulmonary disease; ASA, American Society of Anesthesiologists. ${ }^{a}$ Data for Laurén classification and signet-ring cell were missing in 8 patients. ${ }^{* \star}$ Pearson chi-square test. 
Table 2. Bivariate Cox regression analysis for time to recurrence after curative gastrectomy for adenocarcinoma of the stomach

\begin{tabular}{|c|c|c|c|}
\hline & \multicolumn{3}{|c|}{ Bivariate analysis } \\
\hline & HR & $95 \% \mathrm{Cl}$ & $P$ \\
\hline Gender (male) & 1.28 & $0.83-1.97$ & 0.263 \\
\hline Age, 1 year increment & 1.00 & 0.99-1.02 & 0.346 \\
\hline Weight loss $\geq 10 \%$ & 1.96 & $1.09-3.54$ & 0.025 \\
\hline Cardiac co-morbidities & 0.91 & $0.59-1.40$ & 0.687 \\
\hline ASA score & & & \\
\hline II & 0.77 & $0.46-1.29$ & 0.338 \\
\hline III-IV & 0.81 & $0.42-1.57$ & 0.548 \\
\hline Tumor location (Non-antropyloric vs. antropyloric) & 1.53 & $1.00-2.34$ & 0.049 \\
\hline Adjuvant therapy & 1.41 & $0.93-2.15$ & 0.103 \\
\hline Perioperative transfusion & 1.27 & $0.83-1.93$ & 0.256 \\
\hline Gastrectomy extent (Total vs. subtotal) & 1.58 & $1.03-2.44$ & 0.036 \\
\hline Splenectomy & 1.09 & $0.65-1.81$ & 0.738 \\
\hline Multivisceral resection & 1.08 & $0.64-1.82$ & 0.755 \\
\hline Lymphadenectomy extent (D1 vs D2) & 1.19 & $0.77-1,86$ & 0.424 \\
\hline Laurén (Diffuse vs. non-diffuse) & 1.62 & $1.05-2.49$ & 0.027 \\
\hline Lymphatic invasion & 2.82 & $1.85-4.31$ & $<0.001$ \\
\hline Vascular invasion & 2.07 & $1.31-3.28$ & 0.002 \\
\hline Perineural invasion & 2.38 & $1.53-3.71$ & $<0.001$ \\
\hline Differentiation grade (compared vs. good) & & & \\
\hline Moderate & 2.13 & $0.65-6.94$ & 0.207 \\
\hline Poor & 2.35 & $0.73-7.55$ & 0.150 \\
\hline Signet-ring cell ${ }^{*}$ & 1.49 & $0.83-2.69$ & 0.181 \\
\hline pT category** (compared vs. T1-T2) & & & \\
\hline$p T 3$ & 3.64 & $1.57-8.43$ & 0.002 \\
\hline pT4 & 14.6 & 6.64-32.22 & $<0.001$ \\
\hline pN category** (compared vs. pNO) & & & \\
\hline$p N 1$ & 2.73 & $1.28-5.81$ & 0.009 \\
\hline$p N 2$ & 6.32 & $3.14-12.74$ & $<0.001$ \\
\hline$p N 3$ & 11.53 & $6.25-21.24$ & $<0.001$ \\
\hline pTNM stage $^{* *}$ (compared vs. IA-IIA) & & & \\
\hline IIB-IIIA & 4.70 & $2.16-10.21$ & $<0.001$ \\
\hline$\|I B-\| I C$ & 22.30 & $10.93-45.50$ & $<0.001$ \\
\hline Clavien grade ( $\geq I$ vs.0-I) & 1.13 & $0.73-1.73$ & 0.572 \\
\hline $\mathrm{CCl}$ (per point) & 1.00 & $0.98-1.01$ & 0.886 \\
\hline Sepsis & 1.14 & $0.70-1.84$ & 0.606 \\
\hline Intra-abdominal infection & 1.04 & $0.56-1.91$ & 0.905 \\
\hline Respiratory complications & 1.07 & $0.56-2.01$ & 0.832 \\
\hline
\end{tabular}

Statistically significant results are shown in bold. *According to World Health Organization (WHO) criteria $[16]{ }^{* *}$ According to the 7th edition of the International Union Against Cancer tumor, node metastasis staging system [17]. ASA, American Society of Anesthesiologists; CCI, Comprehensive Complication Index. HR: hazard ratio; $\mathrm{Cl}$ : confidence interval. 
Table 3. Bivariate Cox regression analysis for overall survival after curative gastrectomy for adenocarcinoma of the stomach.

\begin{tabular}{|c|c|c|c|}
\hline & \multicolumn{3}{|c|}{ Bivariate analysis } \\
\hline & HR & $95 \% \mathrm{Cl}$ & $\boldsymbol{P}$ \\
\hline Gender (male) & 1.25 & $0.89-1.73$ & 0.192 \\
\hline Age, 1 year increment & 1.04 & $1.02-1.05$ & $<0.001$ \\
\hline Weight loss $>10 \%$ & 1.66 & $1.03-2.66$ & 0.036 \\
\hline Cardiac co-morbidities & 1.38 & $1.00-1.90$ & 0.047 \\
\hline \multicolumn{4}{|l|}{ ASA score } \\
\hline II & 1.02 & $0.67-1.55$ & 0.916 \\
\hline III-IV & 1.56 & $0.96-2.57$ & 0.075 \\
\hline Tumor location (non (Antropyloric vs. antropyloric) & 1.17 & $0.85-1.61$ & 0.336 \\
\hline Adjuvant therapy & 0.89 & $0.65-1.24$ & 0.506 \\
\hline Perioperative transfusion & 1.38 & $1.00-1.91$ & 0.051 \\
\hline Gastrectomy extent (Total vs. subtotal) & 1.20 & $0.87-1.66$ & 0.258 \\
\hline Splenectomy & 1.07 & $0.73-1.57$ & 0.721 \\
\hline Multivisceral resection & 1.05 & $0.71-1.55$ & 0.814 \\
\hline Lymphadenectomy extent (D1 vs. D2) & 1.20 & $0.86-1.68$ & 0.289 \\
\hline Laurén (Diffuse vs. non-diffuse) & 1.39 & $1.00-1.94$ & 0.051 \\
\hline Lymphatic invasion & 1.74 & $1.24-2.46$ & 0.002 \\
\hline Vascular invasion & 1.47 & $1.00-2.18$ & 0.051 \\
\hline Perineural invasion & 1.83 & $1.27-2.65$ & $<0.001$ \\
\hline \multicolumn{4}{|l|}{ Differentiation grade (compared vs. good) } \\
\hline Moderate & 0.83 & $0.43-1.59$ & 0.538 \\
\hline Poor & 1.03 & $0.55-1.94$ & 0.917 \\
\hline Signet-ring cell ${ }^{*}$ & 1.01 & $0.59-1.72$ & 0.978 \\
\hline \multicolumn{4}{|l|}{ pT category** (compared vs. T1-T2) } \\
\hline pT3 & 1.49 & $0.96-2.39$ & 0.770 \\
\hline pT4 & 4.19 & $2.75-6.38$ & $<0.001$ \\
\hline \multicolumn{4}{|l|}{$\mathrm{pN}$ category ${ }^{\star *}$ (compared vs. pNO) } \\
\hline$p N 1$ & 1.68 & $1.03-2.73$ & 0.037 \\
\hline$p N 2$ & 2.99 & $1.87-4.76$ & $<0.001$ \\
\hline$p N 3$ & 4.87 & 3.23-7.35 & $<0.001$ \\
\hline \multicolumn{4}{|l|}{ pTNM stage ${ }^{* *}$ (compared vs. IA-IIA) } \\
\hline$\| B-I I A$ & 1.81 & $1.17-2.80$ & 0.008 \\
\hline$\|I I B-\| I C$ & 6.80 & $4.56-10.16$ & $<0.001$ \\
\hline Clavien grade ( $\geq$ II vs $0-\mathrm{I}$ ) & 1.21 & $0.87-1.69$ & 0.250 \\
\hline $\mathrm{CCl}$ (per point) & $1-01$ & $1.00-1.02$ & 0.182 \\
\hline Sepsis & 1.19 & 0.83-1.71 & 0.354 \\
\hline Intraabdominal infection & 0.90 & $0.55-1.47$ & 0.660 \\
\hline Respiratory complications & 1.13 & $0.71-1.78$ & 0.611 \\
\hline
\end{tabular}

Statistically significant results are shown in bold. *According to World Health Organization (WHO) criteria ${ }^{1}$ [17] ${ }^{* *}$ According to the 7th edition of the International Union Against Cancer tumor, node metastasis staging system [18]. ASA, American Society of Anesthesiologists; CCI, Comprehensive Complication Index. HR: hazard ratio, $\mathrm{Cl}$ : confidence interval. 
Table 4. Multivariate Cox regression analyses for time to recurrence and overall survival adjusting for patient, disease and treatment factors.

\begin{tabular}{|c|c|c|c|c|}
\hline & \multicolumn{2}{|c|}{ Time to Recurrence } & \multicolumn{2}{|c|}{ Overall Survival } \\
\hline & HR (95\% Cl) & $P$ & HR (95\% Cl) & $P$ \\
\hline \multicolumn{5}{|c|}{ Clavien-Dindo $\geq$ II } \\
\hline${ }^{*}$ Model 1 & $0.93(0.56-1.54)$ & 0.779 & $0.76(0.51-1.12)$ & 0.167 \\
\hline${ }^{* *}$ Model 2 & $0.99(0.49-1.98)$ & 0.971 & $0.72(0.41-1.26)$ & 0.254 \\
\hline \multicolumn{5}{|l|}{ Sepsis } \\
\hline${ }^{*}$ Model 1 & $1.00(0.55-1.83)$ & 0.996 & $1.08(0.70-1.67)$ & 0.724 \\
\hline${ }^{\star *}$ Model 2 & $1.23(0.68-2.25)$ & 0.497 & $1.13(0.73-1.75)$ & 0.578 \\
\hline \multicolumn{5}{|c|}{ Intra-abdominal sepsis } \\
\hline${ }^{*}$ Model 1 & $0.88(0.43-1.82)$ & 0.733 & $0.87(0.49-1.52)$ & 0.619 \\
\hline${ }^{* *}$ Model 2 & $0.96(0.45-2.01)$ & 0.903 & $0.89(0.50-1.56)$ & 0.673 \\
\hline
\end{tabular}

*Adjusted for patient and disease factors (age, gender, cardiovascular co-morbidities, ASA score, weight loss, tumor location, Laurén classification, signet-ring cell, grade of differentiation, lymphatic invasion, vascular invasion, perineural invasion, and pTNM stage).

${ }^{*}$ Adjusted for patient, disease and treatment factors (year of surgery, age, gender, cardiovascular comorbidities, ASA score, Laurén classification, signet-ring cell, grade of differentiation, lymphatic invasion, vascular invasion, perineural invasion, pTNM stage, type of gastrectomy, extent of lymphadenectomy, splenectomy, multivisceral resection, adjuvant therapy, and perioperative blood transfusion). HR: hazard ratio; Cl: confidence interval. 


\section{Legends}

Figure 1. Kaplan-Meier curves comparing time to recurrence and overall survival in patients with and without complications ( $A$ and $C$ ), and in patients with and without sepsis (B and D), respectively. 